\title{
Research on Human Resources Localization in Overseas Engineering Projects--Take the Algerian Project as an Example
}

\author{
Yu Wang ${ }^{1, ~ a, ~ S i j i a ~ J i a n g ~}{ }^{2, b}$ \\ ${ }^{1}$ China Petroleum First Construction Co. LTD., Luoyang 471023, China; \\ ${ }^{2}$ China Petroleum Engineering Construction Co. LTD., Beijing 100120, China. \\ awangyu801202@163.com, b26311979@qq.com
}

Keywords: Overseas engineering projects; human resources; localization.

\begin{abstract}
With the fierce competition of overseas project market, human resources localization has become the only way to sustain the development of overseas engineering projects. Thus, in this paper, the significance of human resources localization is analyzed in terms of the need of the "going global” strategy, the aversion of project risks, the reduction of labor costs, and project communication. In addition, relevant measures for human resources localization are proposed, taking the Algerian refining and chemical construction project as an example.
\end{abstract}

\section{Introduction}

With the continuous progress of global economic integration, especially with the implementation of China's Belt and Road Initiative, more and more Chinese enterprises have gone abroad to undertake international engineering projects. The international engineering project markets have also gradually extended from the traditional regions of Africa, the Middle East and Central Asia to Southeast Asia, Oceania and South America. As the largest country in North Africa, Algeria has the fifth largest natural gas reserves in the world, the 14th largest oil reserves in the world, and the second largest natural gas exporter in the world. It is also located at the crossroad of the Belt and Road and has a rapid economic development. At present, the competition in the Algerian refining and chemical construction market is increasingly fierce. How to gain a project in the Algerian market, gain a firm foothold, expand the market, and achieve development, the localization of human resources is the only choice.

\section{The Connotation of Human Resources Localization}

The localization of human resources refers to the implementation of international engineering projects in accordance with the laws and regulations of local countries, making full use of the human resources of local countries, establishing relevant personnel systems, and recruiting, selecting, training, and using local staff. It also actively cooperates and cooperates with Chinese employees to jointly complete the project construction and production tasks, so as to achieve the goals of saving project costs, improving economic benefits, expanding market share, eliminating cultural barriers, and promoting enterprise development.

The scholar Taming analyzes the importance and necessity of carrying out the localization of human resources in offshore engineering, and puts forward the management measures of local operators in his paper (Tao Ming, 2014). The scholar Zhang Chong expounds the significance of implementing the human resources localization management of overseas projects, analyzes the current situation and existing obstacles of human resources localization management of overseas projects, and puts forward some thoughts and suggestions on the implementation of human resources localization management of overseas projects in his paper (Zhang Chong, 2016). Based on these two scholars' views, this paper takes the construction project of Algerian smelter as an example, and puts forward some suggestions on the implementation of human resource localization in overseas engineering projects. 


\section{The Significance of Human Resources Localization}

\subsection{Needs for the "Going Global" Strategy.}

The Belt and Road Initiative, a major national development initiative, has been accepted by most countries along the routes. Since 2012, the price of crude oil has continued to fall, and the competition in the construction market of overseas smelters has gradually intensified. From the traditional Middle East, Central Asia, Africa to Southeast Asia, Latin America and other regions, the company's construction footprint has spread throughout the company. Since 2017, the company has vigorously contracted for the construction of a refinery in Algeria. The construction and management complexity of the project is unprecedented, and the personnel gap is huge. The local market knows technology, can manage, and can operate. In particular, people with many years of experience in project management are the most effective and economical supplement to us. Therefore, in order to gain a firm foothold in the emerging market, operate project, open up the market, the localization of human resources is our inevitable choice.

\subsection{Human Resources Localization as a Means to Help Reduce Labor Costs.}

For traditional overseas projects, labor costs account for about $25-30 \%$ of the total project budget. However, with the increasingly fierce competition in the global refining project construction market, it is an indisputable fact that the lowest price is awarded, and the implementation of the project must implement a low-cost strategy. In the case of fixed construction equipment rental fees and construction measures, it is only by reducing labor costs that the project can be profitable and the market will develop. In the case of the Algerian project, the income of general engineers is $40 \%$ of domestic personnel, and the operating service posts such as welders and plumbers are only $25 \%$ of domestic personnel. This does not include Visa fees for Chinese personnel, training fees, insurance premiums, and airfares to and from China. For this reason, if the human resources adopt the localization strategy in the project implementation process, it can greatly reduce the human resources cost, thereby improving the profitability of the project, and also ensure that the project is more competitive when bidding.

\subsection{Human Resources Localization as a Means to Help Guard against Risks.}

The overseas refining and chemical engineering projects are basically located in third-world countries and regions with abundant oil and gas resources but relatively underdeveloped economies, such as the Middle East, Africa and Latin America, where regional governments have changed, terrorism, extremism and religious forces have become rampant. Even in a country as low-risk as Algeria, it is important to guard against terrorist attacks. In addition, the natural environment in these areas is harsh, disasters such as heat, floods, and mudslides occur from time to time, and infectious diseases such as malaria, dengue fever, and typhoid fever are prevalent. Most of the frontline managers and technicians are located in the harsh conditions of the Gobi desert, swamps, and hilly areas. They are far from the city and have few people. They have been for several months and have greatly damaged the mental health of project personnel.

Most countries require work visas for foreign project work. It is not allowed to use business visas and tourist visas to participate in the implementation of projects. However, work visas are generally strictly reviewed, the processing cycle is longer, and the number of places is limited.

The implementation of the human resources localization strategy has enabled local employees to adapt to the local environment and climate, can deal with local issues in a timely manner, and saves the trouble of obtaining visas. Once hired, they can start work and effectively avoid the above risks.

\subsection{Human Resources Localization as a Means to Facilitate Project Communication.}

PMPBOOK clearly points out that good communication is a prerequisite for the smooth implementation of the project. Communication skills are not only reflected in the way of communication, communication skills, but also mainly reflected in the effectiveness of communication. Whether it is the owner, supervisor, sub-contractor, or material supplier, they are basically based on the personnel of the country in which they are located, and they basically use their mother tongue for daily communication. Although some Chinese personnel have received training from abroad and have experience in several projects, they can use local languages to communicate 
with relevant personnel. However, based on different thinking styles and cultural backgrounds, communication is difficult to achieve the desired results. The use of localization strategy can eliminate cultural obstacles to the maximum, familiar with the work habits and characteristics of local employees, can improve the efficiency and effectiveness of human resources management in the country where they are stationed, and is conducive to reducing and mitigating management contradictions and inefficiencies caused by cultural differences. Native workers have also accumulated various resource relationships and are very knowledgeable about local market information and the supply of labor, so they can go deep into all walks of life and various levels in the local area.

\section{Implementation of Human Resources Localization}

\subsection{Hierarchical Model of Localized Human Resources.}

At present, CPFCC has employed local employees for overseas projects. The main projects or participating units employ technicians, welders, plumbers, and general workers to be integrated into the management of local professional service companies. In order to avoid tax, legal and security risks related to the construction process, information such as basic information, communication address, contact phone number, work performance, suitable job, etc. of highly capable personnel are entered into the information base to facilitate the rapid collection of resources in the preparation of new projects. In the process of implementation, all departments are required to fully trust and effectively use local personnel to maximize the strength of Chinese managers on the scene.

\subsection{The Necessity to Develop the "Down-To-Earth" Management Systems Regarding Local Employees.}

Given different backgrounds, the foreign personnel management methods and remuneration systems are very different from those in China. Take the Algerian project as an example; due to a large number of religious beliefs in Algeria, there are a large number of festivals throughout the year. In addition, due to a lack of the sense of time, the local people are generally inefficient in their work. In establishing personnel management measures, we should first respect the religious practices of the local people and arrange humane work systems; second, clarify the duties and responsibilities of each position, establish a clear reward and punishment system, and cooperate with effective performance evaluation methods to motivate local employees. Give full play to the initiative and enthusiasm of his work. For managers, professional technicians, and operating technicians, respectively, set up management, technical, and operational service promotion channels, promote capable localized employees, and help localized employees obtain professional achievement to the maximum extent.

\subsection{Human Resources Localization Must Comply With Local Laws and Regulations.}

Foreign governments are very strict with employee management, and they have complicated procedures. In the Arab countries in particular, the employment system is very complex and there are many potential risks. To avoid relevant disputes and fines, the local labor laws must be thoroughly studied and strictly followed. First, the pension funds shall be paid for the local employees. The employment \& labor laws provide an extremely high level of protection for local laborers. According to these laws, local companies are required to pay corresponding pension funds for their employees on a monthly basis. The labor departments in all regions will irregularly check the labor information of the companies within the region without any prior notice or announcement. Any company found to have failed to pay the pension funds in a timely manner will be financially penalized by the labor department depending on the actual situation. In case the company refuses to pay the pension funds, it will be sued by the labor department and added to its blacklist, in which case, the company will possibly be forced to terminate its business in local. In addition, as one of the important materials for applying for progress payments, the contractor must timely submit monthly labor information (namely, monthly PF payment vouchers), and any failure to do so will entitle the employer to refuse to pay such amounts. Second, the enterprise must pay WCP (Workers' Compensation Program, a type of accidental injury insurance). To ensure the safety of local workers, the local employment \& labor 
laws request that the contractors cover all the construction workers on site (both Chinese workers and local workers) against accidental injuries (WCP). It is important to note that the insurance covers all the workers on the construction site on a day instead of all of the workers employed. At the beginning of the project, the contractor is required to submit to the employer the documents certifying WCP payment. Otherwise, the employer will have the right to refuse to pay the progress payment.

\subsection{Respect for Local Cultural Diversity.}

Cultural diversity must be respected in the management of localization of personnel. First of all, we should thoroughly understand the local cultural traditions, religious beliefs and customs, compare the differences between them and our culture, and analyze the impact that cultural differences may have on the project personnel, so as to avoid cultural conflicts. Secondly, the project should respect the local culture; avoid insulting the local religion, and make local employees feel respected. To guide good local staff to follow the project schedule, subject to project management. On the occasion of the national holiday, the project department should offer condolences to local employees. On the occasion of major festivals in China, local employees are also invited to bring their families to the celebration. In daily work, localized employees are fully respected and treated equally. Localized employees can participate in the discussion of various project decisions and provide opinions and suggestions on the implementation of the project. Through the creation of cultural exchange platforms, cultural exchange activities, increasing the communication between employees from different cultural backgrounds, and achieving friendly relations with local employees.

\section{Conclusion}

With the increasing competition in the overseas engineering construction market and the low-cost strategy implemented by enterprises, the localization of human resources has become an inevitable trend in the implementation of overseas engineering projects. It is necessary to accumulate the experience of localization of human resources, improve the project management system, and integrate the local National human resources management culture to further explore overseas markets and achieve overseas survival and development.

\section{References}

[1]. Tao Ming. Research on human resources management of overseas projects of China Jiao tong University Aviation Administration [J]. Operations Manager, 2014(1): 192-194.

[2]. Zhang Chong. Exploration of Human Resources Management of an Overseas Engineering Project of the Aviation Authority [J]. Economist, 2016(6): 235-237.

[3]. Cui Jibe. Research on the localization of overseas human resources of Chinese enterprises [D].Beijing: Beijing Jiao tong University, 2015. 